\title{
TNF- $\alpha$ promotes colon cancer cell migration and invasion by upregulating TROP-2
}

\author{
PENG ZHAO and ZHONGTAO ZHANG
}

\author{
Department of General Surgery, Beijing Friendship Hospital, Capital Medical University, Beijing 100050, P.R. China
}

Received March 3, 2017; Accepted October 24, 2017

DOI: $10.3892 / 01.2018 .7735$

\begin{abstract}
High levels of tumor-associated calcium signal transduction protein (TROP)-2 have been demonstrated to be strongly associated with tumor necrosis factor (TNF)- $\alpha$ levels in colon cancer. In the present study, the effect of TNF- $\alpha$ on the regulation of TROP-2 expression and its effect in colon cancer cell migration and invasion were investigated in vitro. TROP-2 protein levels were evaluated in HCT-116 human colon cancer cells cultured with various concentrations of TNF- $\alpha$ using western blot analysis. Changes in the migratory and invasive potential of the cells were evaluated using a wound healing and transwell assay, respectively. Then, TROP-2 expression was downregulated in cells by use of siRNA, and TROP-2 knockdown was confirmed at the mRNA and protein level by reverse transcription-quantitative polymerase chain reaction and western blotting, respectively. The migration and invasion potential of cells transfected with TROP-2 siRNA was also evaluated. Levels of several mitogen-activated protein kinase proteins, namely p38, c-Jun $\mathrm{N}$-terminal kinase (JNK) and extracellular signal-regulated kinase (ERK), were detected in cells treated with TNF- $\alpha$ using western blot analysis. The results demonstrated that TROP-2 protein levels increased in cells treated with lower concentrations of TNF- $\alpha$, but decreased in cells treated with higher concentrations of TNF- $\alpha$, compared with untreated control. Maximum TROP-2 levels were observed in cells treated with $20 \mu \mathrm{g} / 1 \mathrm{TNF}-\alpha$. Migration and invasion were enhanced in cells treated with $20 \mu \mathrm{g} / 1 \mathrm{TNF}-\alpha$. When TROP-2 was silenced in colon cancer cells by siRNA, migration and invasion were significantly decreased compared with control cells. TNF- $\alpha$ stimulation activated the ERK1/2 pathway,
\end{abstract}

Correspondence to: Dr Zhongtao Zhang, Department of General Surgery, Beijing Friendship Hospital, Capital Medical University, 95 Yongan Road, Xicheng, Beijing 100050, P.R. China

E-mail: zhaopeng963@126.com

Abbreviations: TNF- $\alpha$, tumor necrosis factor- $\alpha$; TROP-2, tumor-associated calcium signal transducer protein-2

Key words: colon cancer, tumor necrosis factor- $\alpha$, tumor-associated calcium signal transduction protein-2, tumor invasion, metastasis but did not significantly affect p38 and JNK phosphorylation levels. Treatment with a specific ERK1/2 inhibitor suppressed the TNF- $\alpha$-induced upregulation of TROP- 2 and the TNF- $\alpha$-induced colon cancer cell migration and invasion. In conclusion, the present results demonstrated that low concentrations of TNF- $\alpha$ significantly enhanced colon cancer cell migration and invasion by upregulating TROP-2 via the ERK1/2 signaling pathway.

\section{Introduction}

Colon cancer is a common malignant tumor of the digestive tract, from which morbidity and mortality have been increasing in recent years. Tumor invasion and metastasis are the main causes of colon cancer-associated death, but the precise mechanism mediating these processes remains unclear. Previous studies have primarily focused on the characteristics of cancer cells; however, the effects of the tumor microenvironment on invasion and metastasis have increasingly been gaining attention in recent years (1).

The tumor microenvironment has an important role in tumorigenesis and disease progression. Tumor necrosis factor (TNF)- $\alpha$ is an inflammatory cytokine frequently present in the tumor microenvironment. TNF- $\alpha$ is primarily secreted by tumor-associated macrophages and it initiates chronic inflammation (2). TNF- $\alpha$ has biphasic effects, by which it induces tumor cell apoptosis at high doses while it accelerates tumor invasion and metastasis with long-term administration of low doses (3). Tumor cell invasion is potentiated when tumor cells are co-cultured with macrophages, an effect primarily mediated by the secretion of TNF- $\alpha$ by macrophages (4). In addition, TNF- $\alpha$ induces the expression of angiogenic factors, promotes tumor angiogenesis, and accelerates tumor metastasis (5). However, the specific molecular mechanisms by which TNF- $\alpha$ facilitates tumor cells migration and invasion are unclear.

Tumor-associated calcium signal transducer protein (TROP)-2 is a transmembrane glycoprotein expressed at high levels in a variety of human epithelial tumors, including oral (6), pancreatic (7), gastric (8), ovarian (9), lung (10), and prostate cancer (11). By contrast, TROP-2 is barely detectable in non-cancerous tissues. Furthermore, TROP-2 is strongly associated with tumor invasion and metastasis, and with disease prognosis $(12,13)$. A previous study from our group have demonstrated that both TROP- 2 and TNF- $\alpha$ levels are 
elevated in colon cancer cells and that TROP-2 and TNF- $\alpha$ levels are directly associated (12). The aim of the present study was to explore the effect of TNF- $\alpha$ on the regulation of TROP-2 levels in the context of colon cancer cell migration and invasion.

\section{Materials and methods}

Cells and reagents. The human colon cancer cell line HCT-116 was kindly provided by Professor Haitao Shen (Department of Pathology, Hebei Medical University, Hebei, China). The cells were frozen in liquid nitrogen. Recombinant human TNF- $\alpha$ was purchased from Sigma-Aldrich (Merck KGaA, Darmstadt, Germany). The Lipofectamine 2000 transfection kit was purchased from Invitrogen (Thermo Fisher Scientific, Inc., Waltham, MA, USA). TROP-2 small interfering (si)RNA (5'-CGT GGACAACGATGGCCTCTA-3') and the negative control siRNA (5'-UUCUCCGAACGUGUCACGUTT-3') were purchased from Biovol Biotechnology (Shanghai, China). Matrigel, a mixture of basement membrane matrix proteins, was purchased from BD Biosciences (Franklin Lakes, NJ, USA). Monoclonal mouse anti-human primary TROP-2 antibody (cat. no. ab65006; 1:1,000) and GAPDH antibody (cat. no. ab8245; 1:1,000) were purchased from Abcam (Cambridge, MA, USA). Monoclonal mouse antibodies against human phosphorylated (p)-c-Jun N-terminal kinase (JNK; cat. no. 9251; 1:1,000), total (t)-JNK (cat. no. 9252; 1:1,000), p-p38 (cat. no. 9211; 1:1,000), t-p38 (cat. no. 9212; 1:1,000), p-extracellular signal-regulated kinase (p-ERK) $1 / 2$ (cat. no. 9101; 1:1,000), and t-ERK1/2 (cat. no. 9107; 1:1,000) were purchased from Cell Signaling Technology, Inc. (Danvers, MA, USA). The specific p-ERK1/2 inhibitor PD98059 was purchased from Cayman Chemical Company (Ann Arbor, MI, USA). Horseradish peroxidase-conjugated secondary antibody was purchased from Beijing Zhongshan Jinqiao Biotechnology Co., Ltd. (1:4,000; Beijing, China).

Cell culture. HCT-116 human colon cancer cells were cultured in McCoy's 5A medium (Gibco; Thermo Fisher Scientific, Inc., Waltham, MA, USA) supplemented with $10 \%$ fetal bovine serum (Invitrogen; Thermo Fisher Scientific, Inc.) and $1 \%$ antibiotics (penicillin and streptomycin). The cells were incubated at $37^{\circ} \mathrm{C}$ in a $5 \% \mathrm{CO}_{2}$ atmosphere.

Western blot analysis. HCT-116 cells were seeded in culture dishes $\left(5 \times 10^{5}\right.$ cells/dish) and cultured until they reached $80 \%$ confluence. Then, the cells were cultured in serum-free medium for an additional $24 \mathrm{~h}$. The cells were subsequently incubated with various concentrations of TNF- $\alpha$ for the indicated period of time. Once cells were harvested, total proteins $(50 \mu \mathrm{g})$ were separated using SDS-PAGE (10\% gel) and the separated proteins were transferred to polyvinylidene fluoride membranes. The membranes were blocked with $5 \%$ skim milk at room temperature for $1 \mathrm{~h}$, and subsequently incubated at $4^{\circ} \mathrm{C}$ overnight with the primary antibody of interest and anti-GAPDH as a loading control. Then, the membranes were washed three times with TBS/0.1\% Tween-20 and incubated with goat anti-rabbit secondary antibody at room temperature for $2 \mathrm{~h}$. The protein signals were detected using enhanced chemiluminescence (Beyotime Institute of Biotechnology, Haimen, China). Western blot results were analyzed using ImageJ software (version 1.41; National Institutes of Health, Bethesda, MD, USA).

Wound healing assay. HCT-116 cells in the logarithmic phase were seeded in 6-well plates. Once the cells reached $80 \%$ confluence, wounds were generated by scratching the cells with a $100-\mu 1$ pipette tip. Then, cells were washed with PBS and treated with TNF- $\alpha$ at a final concentration of $20 \mu \mathrm{g} / \mathrm{l}$ in serum-free medium for $24 \mathrm{~h}$. Control cells were treated with PBS in serum-free medium. Images of the cells were captured at 0 and $24 \mathrm{~h}$ after the wound was created. The width of the wound at 5 randomly selected sites was measured using a Leica TCS-SP5 confocal microscope (magnification, x200; Leica Microsystems, Inc., Buffalo Grove, IL, USA), and the average wound width was calculated. The wound healing rate was calculated using Image J (version 2.1; National Institutes of Health) (14). The experiment was conducted in triplicate.

Transwell invasion assay. The invasive ability of cells was assessed using a Transwell assay. The invasive potential of HCT-116 cells was assessed by determining the number of cells that passed through a polycarbonate membrane $(8 \mu \mathrm{m}$ pore size) in 24-well transwell chambers. The upper Transwell filters (Corning Inc., Corning, NY, USA) were coated with Matrigel (BD Biosciences). Single cell suspensions of HCT-116 cells were cultured until they reached the logarithmic phase, and the cells $\left(1 \times 10^{5}\right)$ were subsequently seeded into the upper chamber of Transwell filters in serum-free medium supplemented with $20 \mu \mathrm{g} / 1 \mathrm{TNF}-\alpha$. Complete medium was added to the lower chambers. The cells were incubated for $24 \mathrm{~h}$, and non-migratory cells on the upper side of the filter were removed using cotton swabs. Cells that had migrated through the pores of the filter were fixed in methanol at $4^{\circ} \mathrm{C}$ for $20-30 \mathrm{~min}$, stained with $0.1 \%$ crystal violet for $30 \mathrm{~min}$ at $37^{\circ} \mathrm{C}$, and washed with PBS. The number of migratory cells was determined using an inverted light microscope at a magnification of $x 200$. The average number of cells in five randomly selected fields was calculated, and the experiment was conducted in triplicate.

siRNA-mediated silencing of TROP-2. In order to knock-down endogenous TROP-2 expression, TROP-2-specific siRNA was transfected into cells using Lipofectamine ${ }^{\circledR} 2000$ transfection reagent (Invitrogen; Thermo Fisher Scientific, Inc.) according to the manufacturer's instructions. Sequences were as follows: TROP-2 siRNA, 5'-CGTGGACAACGATGGCCTCTA-3'; control siRNA, 5'-UUCUCCGAACGUGUCACGUTT-3'. Cells were transfected with TROP-2 siRNA (50 nM) or negative control siRNA (50 nM) using Lipofectamine ${ }^{\circledR} 2000$. Non-transfected cells (blank control group) were included in the analysis. Two days after transfection, transfected cells were harvested and TROP-2 mRNA and protein expression was evaluated by reverse transcription-quantitative polymerase chain reaction and western blot analysis.

$R T$ - $q P C R$. RT-qPCR was used to determine TROP-2 mRNA expression levels of the human colon cancer HCT-116 cell line. 


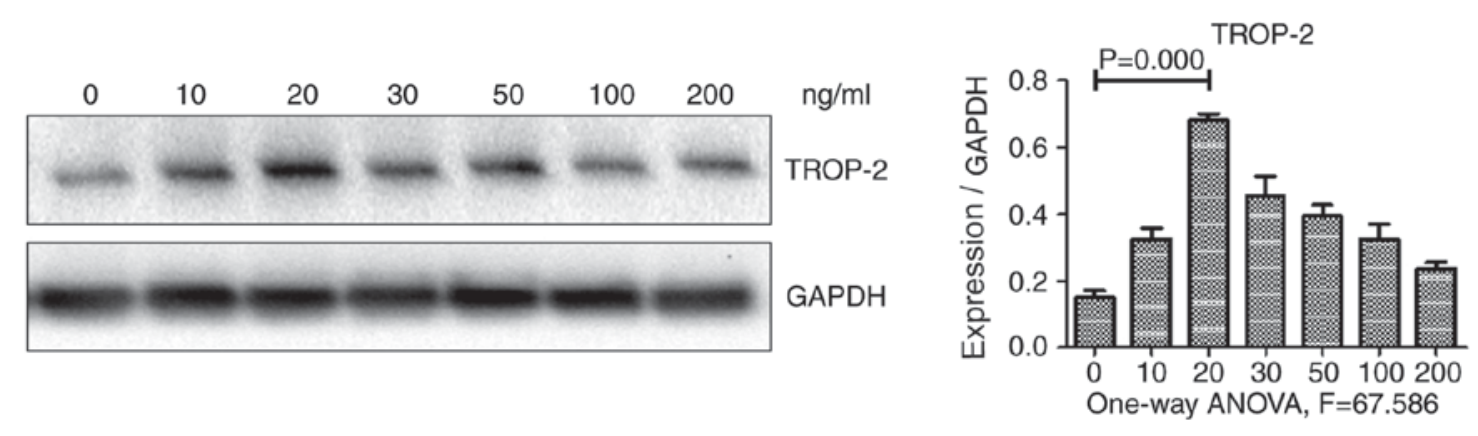

Figure 1. TROP-2 protein levels in HCT-116 cells treated with various concentrations of TNF- $\alpha$. Representative images from the western blot analysis and quantification of the protein signal relative to the GAPDH loading control are demonstrated. TROP-2, tumor-associated calcium signal transducer protein-2; TNF- $\alpha$, tumor necrosis factor- $\alpha$.

Primers were as follows: TROP-2 forward, 5'-TCACCAACC GGAGAAAGTCG-3' and reverse, 5'-AGGAAGCGTGACT CACTTGG-3'; $\beta$-actin forward, 5'-CACGAAACTACCTTC AACTCC-3' and reverse, 5'-CATACTCCTGCTTGCTGA TC-3'. Following transfection, HCT-116 cells were harvested for total RNA extract using TRIzol reagent (Invitrogen; Thermo Fisher Scientific, Inc.). For reverse transcription, RNase-free EP tubes containing Mix I (5 $\mu$ l total RNA, $0.5 \mu$ l of $50 \mu \mathrm{mol} / 1 \mathrm{oligo}(\mathrm{dT}), 0.5 \mu \mathrm{l}$ random primer, $1 \mu \mathrm{l}$ of $10 \mathrm{mmol} / \mathrm{l}$ dNTP solution and $5 \mu 1$ diethylpyrocarbonate-treated water) were incubated in a $65^{\circ} \mathrm{C}$ water bath for $5 \mathrm{~min}$ and immediately transferred to ice water for $1 \mathrm{~min}$. Then, $4 \mu \mathrm{l}$ of $5 \mathrm{X}$ first-strand buffer, $2 \mu 1$ of $0.1 \mathrm{~mol} / 1 \mathrm{DTT}, 1 \mu \mathrm{l}$ of $40 \mathrm{U} / \mu \mathrm{l}$ RNaseOUT (Invitrogen; Thermo Fisher Scientific, Inc.), and $1 \mu 1$ SuperScript III reverse transcriptase (Invitrogen; Thermo Fisher Scientific, Inc.) were added to Mix I for a total reaction volume of $20 \mu \mathrm{l}$. The reactions were incubated as follows: $5^{\circ} \mathrm{C}$ for $5 \mathrm{~min}, 50^{\circ} \mathrm{C}$ for $60 \mathrm{~min}$, and $70^{\circ} \mathrm{C}$ for $15 \mathrm{~min}$. The resulting cDNA products were placed on ice immediately following the reaction. qPCR was performed using SYBR Premix DimerEraser (Takara Biotechnology Co., Ltd., Dalian, China). The conditions for the qPCR were as follows: $50^{\circ} \mathrm{C}$ for $30 \mathrm{~min}$, a denaturation step at $95^{\circ} \mathrm{C}$ for $2 \mathrm{~min}, 40$ cycles of $95^{\circ} \mathrm{C}$ for $10 \mathrm{sec}$ and $60^{\circ} \mathrm{C}$ for $30 \mathrm{sec}$, and an elongation step at $70^{\circ} \mathrm{C}$ for $30 \mathrm{sec}$. All experiments were conducted in triplicate. Relative gene expression levels were calculated using the $2^{-\Delta \Delta \mathrm{Cq}}$ method (15).

Statistical analysis. SPSS software (version 17.0; SPSS, Inc., Chicago IL, USA) was used for statistical analyses. Data with a normal distribution are presented as the mean \pm standard deviation. A t-test was used to compare differences in means between two groups. One-way ANOVA was used to compare differences in means among multiple groups, and the student Newman-Keuls-q method was used for multiple comparisons between groups. $\mathrm{P}<0.05$ was considered to indicate a statistically significant difference.

\section{Results}

Effect of TNF- $\alpha$ on TROP-2 levels in colon cancer cells. Previous studies from our group have demonstrated that TNF- $\alpha$ and TROP-2 protein levels are abundant in colon cancer, and higher levels of these proteins are associated with a poor prognosis (12). To investigate the effect of TNF- $\alpha$ on TROP-2 expression, HCT-116 colon cancer cells were incubated with various concentrations of TNF- $\alpha$, and TROP- 2 protein levels were subsequently examined using western blot analysis. As illustrated in Fig. 1, TROP-2 protein expression levels exhibited a biphasic response, increasing in cells incubated with decreased concentrations of TNF- $\alpha$ (10 and $20 \mu \mathrm{g} / \mathrm{l})$, but decreasing in cells incubated with increased concentrations (30, 50, 100 and $200 \mu \mathrm{g} / \mathrm{l})$. TROP-2 protein levels were the highest in cells incubated with $20 \mu \mathrm{g} / 1 \mathrm{TNF}-\alpha$. These results demonstrated that low concentrations of TNF- $\alpha$ upregulated TROP-2 expression in HCT-116 cells. Therefore, TNF- $\alpha$ at a concentration of $20 \mu \mathrm{g} / 1$ was used in the subsequent experiments.

Effect of TNF- $\alpha$ on TROP-2 regulation. Little is known about the signaling pathways that mediate TNF- $\alpha$-induced upregulation of TROP-2. The mitogen-activated protein kinase (MAPK) signaling pathway is involved in multiple biological processes in tumors, including cell proliferation, cell cycle regulation, migration, and invasion. Since the MAPK pathway can be activated by a variety of inflammatory cytokines and TROP-2 is associated with aggressive tumor cell behaviors, the role of MAPK signaling in TNF- $\alpha$-mediated regulation of TROP-2 was investigated. JNK, p38, and ERK1/2 are key members of the MAPK signaling pathway. As illustrated in Fig. 2, p-ERK1/2 levels increased in cells treated with TNF- $\alpha$ at 15 min post-stimulation, whereas there were no significant changes in p-JNK and p-p38 levels. Fig. 3 demonstrates that, compared with cells treated with TNF- $\alpha$ alone, p-ERK $1 / 2$ and TROP-2 protein levels significantly decreased in cells that were pretreated with the specific ERK1/2 inhibitor PD98059 $(20 \mu \mathrm{M})$ for $30 \mathrm{~min}$. Together, the present data suggested that TNF- $\alpha$ stimulation upregulated TROP-2 protein expression levels by activating the ERK1/2 signaling pathway.

$T N F-\alpha$ promotes colon cancer cell migration and invasion by upregulating TROP-2. Aggressive cancer cells are characterized by an increase in cell migration and invasion abilities. To investigate the role of TNF- $\alpha$ in metastasis, the effect of TNF- $\alpha$ stimulation on migration and invasion of HCT-116 cells was evaluated using and wound healing and transwell assays, respectively. As presented in Fig. 4, the rate of 

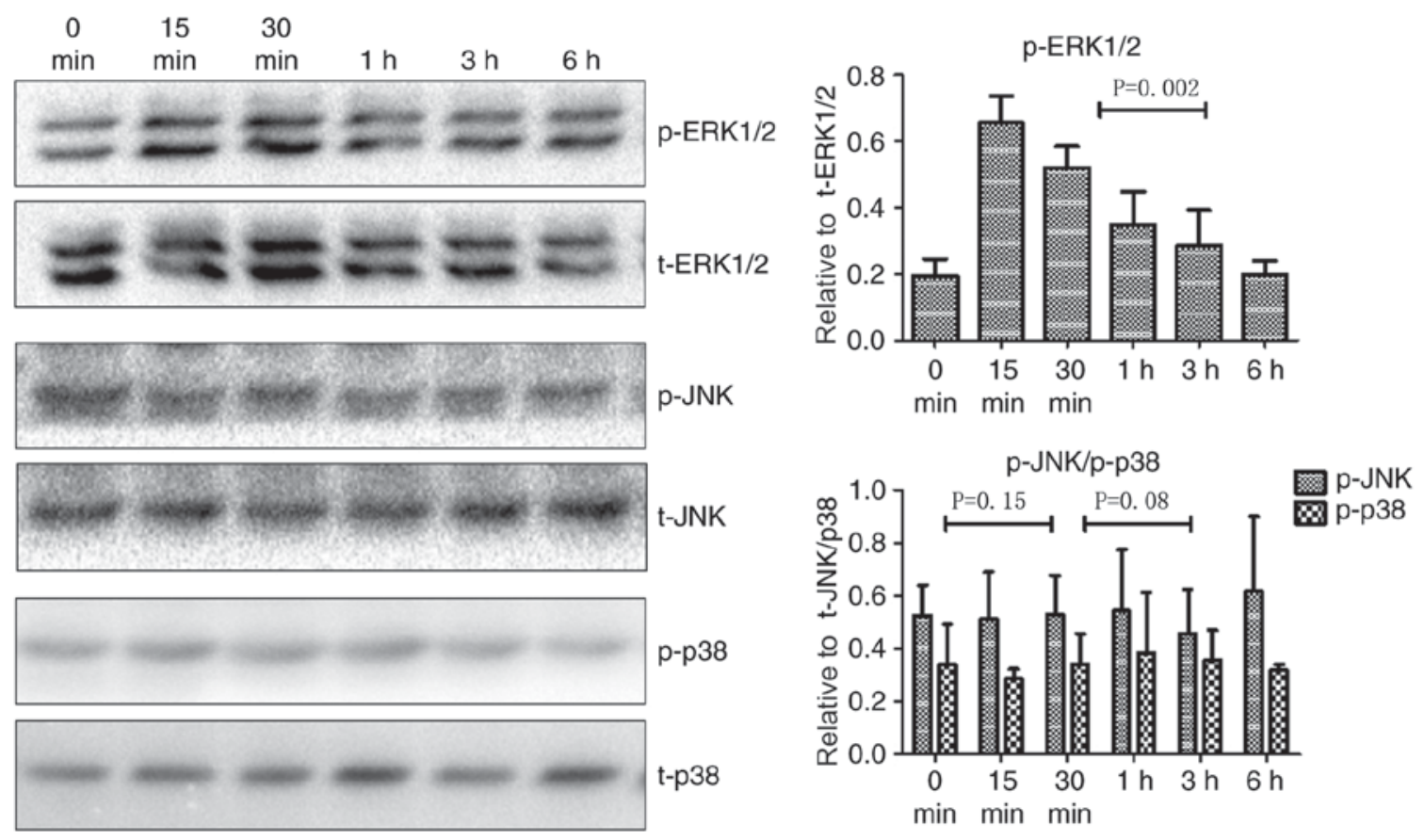

Figure 2. Effect of TNF- $\alpha$ on mitogen-activated protein kinase pathway activation. HCT-116 cells were treated with $20 \mathrm{ng} / \mathrm{ml}$ TNF- $\alpha$ for various time-points, and then protein levels of p-ERK1/2, p-JNK and p-p38 were analyzed by western blotting. Representative images and quantification of the p-relative to the t-levels for each molecule are presented. TNF- $\alpha$, tumor necrosis factor- $\alpha$; p, phosphorylated; t, total; ERK, extracellular signal-regulated kinase; JNK, c-Jun N-terminal kinase.
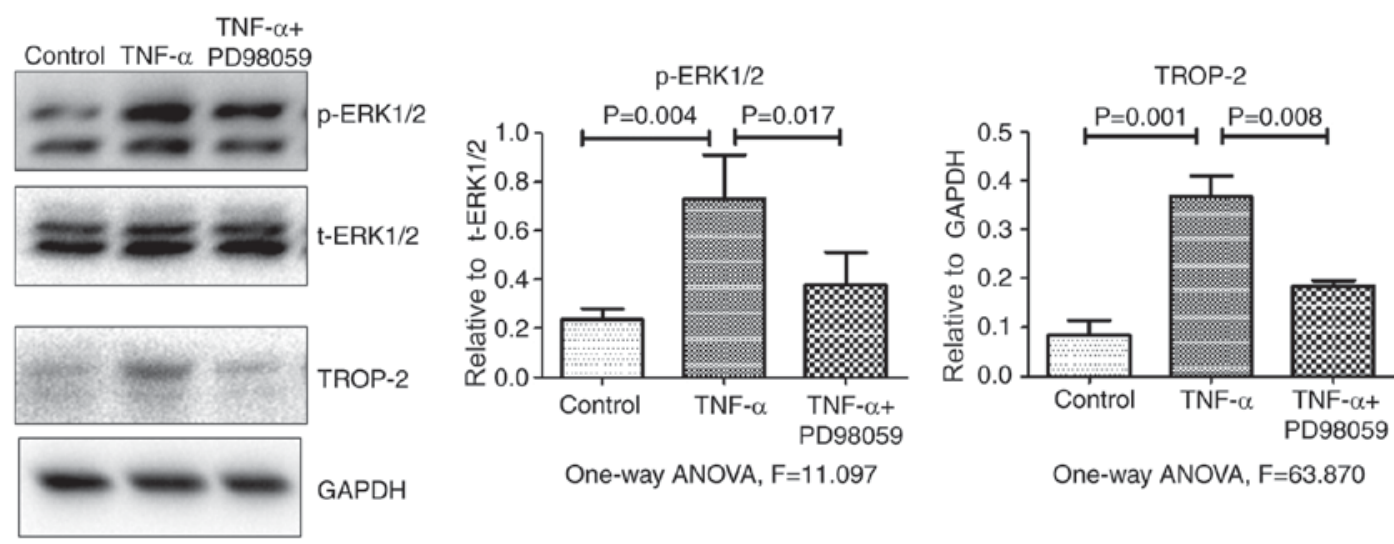

Figure 3. TROP-2 and p-ERK1/2 levels in cells pretreated with the ERK1/2 inhibitor PD98059. Representative images from the western blot analysis and quantification are presented. TROP-2, tumor-associated calcium signal transducer protein-2; p, phosphorylated; ERK, extracellular signal-regulated kinase; TNF- $\alpha$, tumor necrosis factor- $\alpha$; $\mathrm{t}$, total.

wound healing and the number of invasive cells at $24 \mathrm{~h}$ were significantly increased in the TNF- $\alpha$-treated group compared with the control group. These results indicated that TNF- $\alpha$ significantly enhanced the migratory and invasive potential of HCT-116 colon cancer cells.

Although it was demonstrated that TNF- $\alpha$ upregulated TROP-2 protein levels and enhanced the invasive potential of colon cancer cells, it remained unclear if the latter effect was mediated by the upregulation of TROP- 2 . Therefore, the role of TROP- 2 in the TNF- $\alpha$-induced migration and invasion of colon cancer cells was examined by silencing TROP-2 expression with a specific siRNA. The negative control group was transfected with a non-specific scrambled siRNA, and non-transfected cells were used as a blank control. As presented in Table I and Fig. 5, TROP-2 expression levels in cells transfected with TROP-2 siRNA significantly decreased at both the mRNA and protein level compared with control groups. When migration and invasion were examined, the rate of TNF- $\alpha$-induced wound healing and number of invasive cells at $24 \mathrm{~h}$ were significantly decreased in the TROP-2 siRNA group compared with the negative control siRNA group (Fig. 6). In addition, the rate of TNF- $\alpha$-induced wound healing and invasion significantly decreased in cells pretreated with PD98059 $(20 \mu \mathrm{M})$ for 30 min, compared with cells treated with TNF- $\alpha$ alone (Fig. 7). These data demonstrated that TROP-2 knockdown inhibited TNF- $\alpha$-induced invasion and migration in colon cancer cells, and that TNF- $\alpha$ promoted invasion and migration in colon cancer cells by 

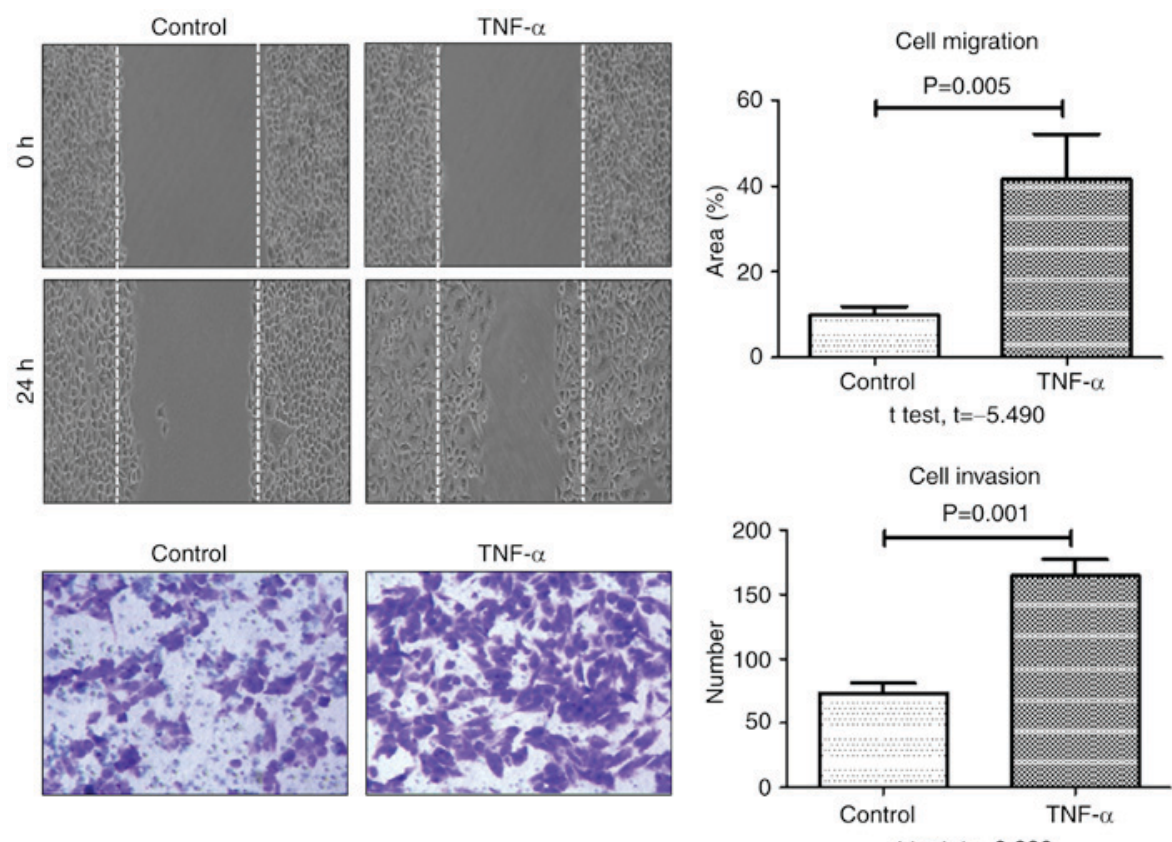

Figure 4. Effect of TNF- $\alpha$ on migration and invasion of HCT-116 cells. Representative images and quantification of wound healing rate (magnification, $\mathrm{x} 100$ ) and Transwell invasion (magnification, $\mathrm{x} 200$ ). TNF- $\alpha$, tumor necrosis factor- $\alpha$.
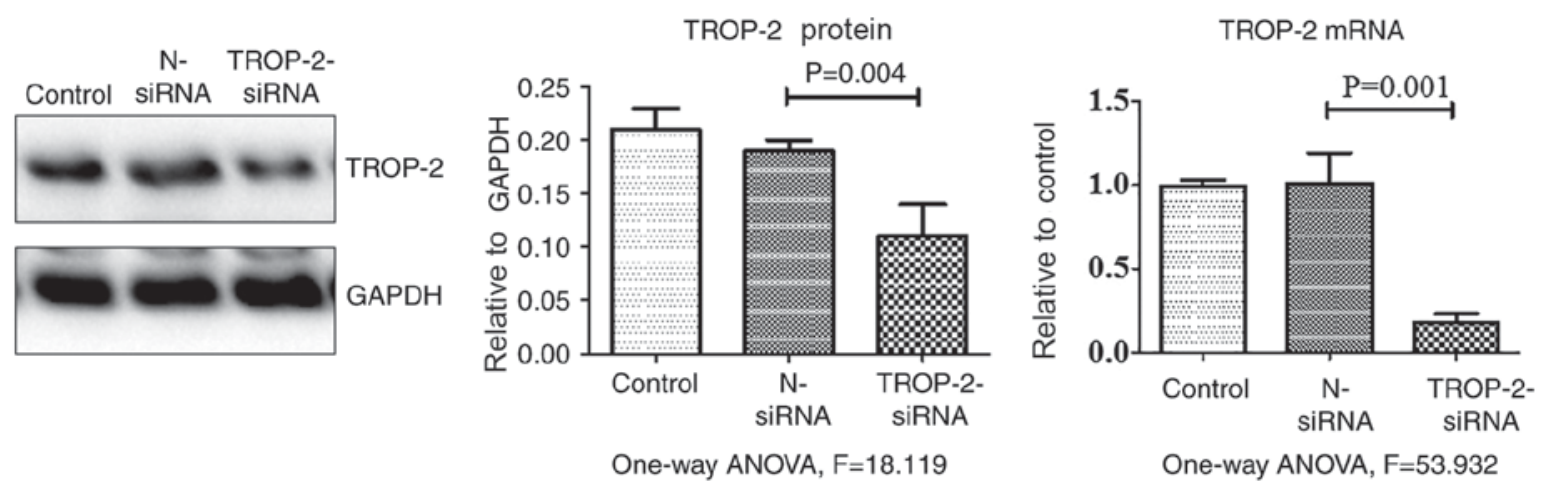

Figure 5. TROP-2 silencing by siRNA. TROP-2 mRNA and protein levels were measured in HCT-116 cells transfected with either a TROP-2-specific siRNA or N-siRNA. Non-transfected cells were used as a blank control (control). TROP-2, tumor-associated calcium signal transducer protein-2; siRNA, small interfering RNA; N, negative control.

Table I. Relative expression levels and mean band intensities of TROP-2 mRNA and protein levels in cells transfected with TROP-2 siRNA.

\begin{tabular}{lcc}
\hline Group & TROP-2 mRNA & TROP-2 protein \\
\hline siRNA & $0.02 \pm 0.01^{\mathrm{a}}$ & $0.10 \pm 0.04^{\mathrm{a}}$ \\
Negative control & $1.02 \pm 0.02^{\mathrm{a}}$ & $0.19 \pm 0.01^{\mathrm{a}}$ \\
Blank control & $1.00 \pm 0.01^{\mathrm{a}}$ & $0.21 \pm 0.02^{\mathrm{a}}$ \\
P-value & 0.001 & 0.004 \\
\hline
\end{tabular}

TROP-2, tumor-associated calcium signal transducer protein-2; siRNA, small interfering RNA. Data was shown as mean \pm standard deviation. ${ }^{\mathrm{a}} \mathrm{P}<0.001$ vs. control group.

upregulating TROP-2 protein expression via the ERK1/2 signaling pathway.

\section{Discussion}

The tumor microenvironment is a popular topic in cancer research, and scholars consider tumor-associated inflammation as the seventh hallmark of cancer (16). The inflammatory microenvironment is strongly associated with tumorigenesis and cancer progression; however, the mechanism by which it promotes invasion and metastasis remains unclear. TNF- $\alpha$ is a key inflammatory cytokine present in the tumor microenvironment. Although TNF- $\alpha$ has been linked to tumor invasion and metastasis, the specific mechanisms underlying this association are unclear. Previous studies have demonstrated that TNF- $\alpha$ can activate the MAPK/ERK pathway, upregulate matrix metallopeptidase (MMP)-9, CD26 and fibroblast activation protein (FAP)- $\alpha$ levels, and enhance tumor cell invasion and metastasis in breast cancer (17). TNF- $\alpha$ may also upregulate MMPs in oral cancer cells, thereby promoting invasion and metastasis (18). 

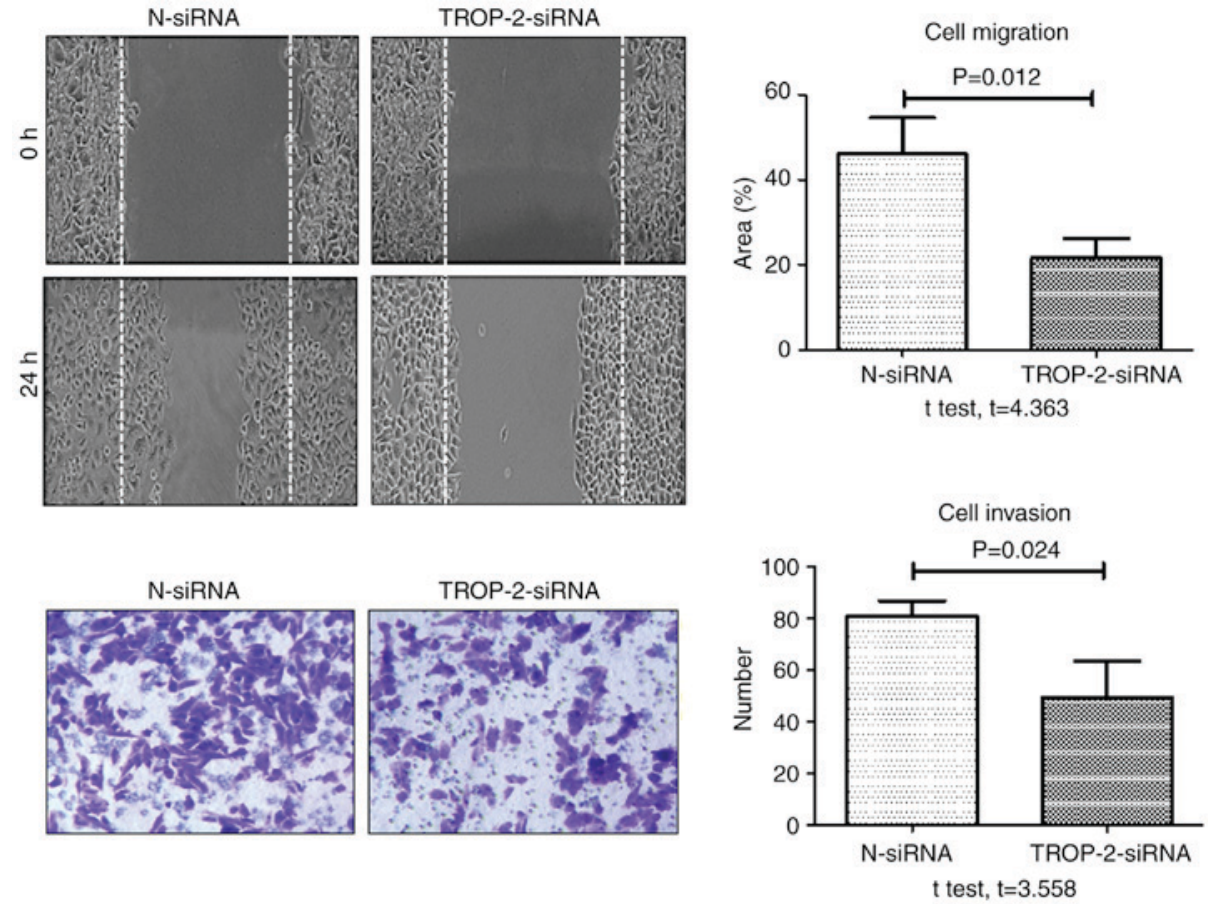

Figure 6. Effect of TNF- $\alpha$ on migration and invasion of TROP-2 silenced HCT-116 cells. Representative images and quantification of wound healing rate (magnification, x100) and Transwell invasion (magnification, $\mathrm{x} 200$ ). TNF- $\alpha$, tumor necrosis factor- $\alpha$; TROP-2, tumor-associated calcium signal transducer protein-2; siRNA, small interfering RNA; N, negative control.
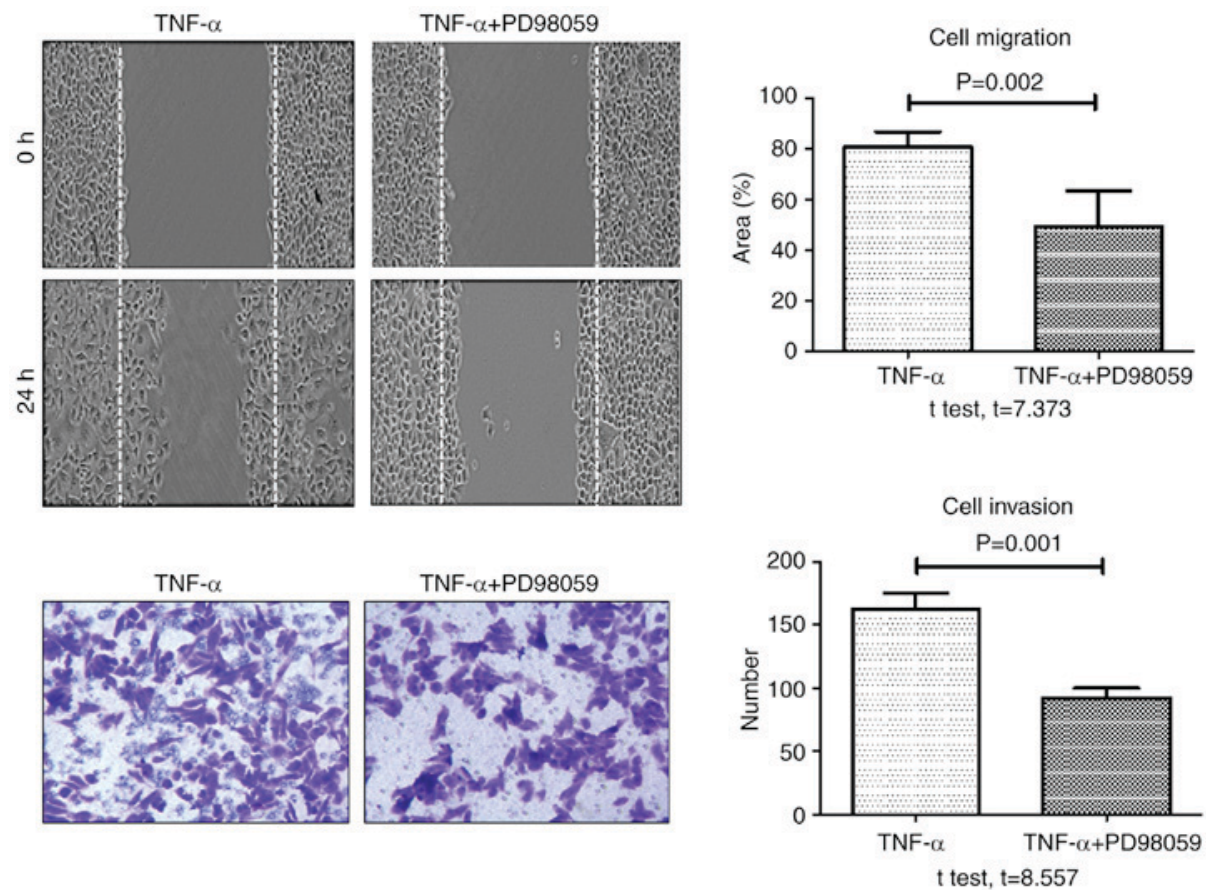

Figure 7. Effect of the ERK1/2 inhibitor PD 98059 on migration and invasion of TNF- $\alpha$-stimulated HCT-116 cells. Representative images and quantification of wound healing rate (magnification, x100) and Transwell invasion (magnification, x200). ERK, extracellular signal-regulated kinase; TNF- $\alpha$, tumor necrosis factor- $\alpha$.

In addition, TNF- $\alpha$ promotes lymphangiogenesis and lymphatic metastasis in gallbladder carcinoma by activating the ERK1/2 or the activator protein-1/vascular endothelial growth factor (VEGF)-D pathway (19). However, there are no previous reports describing the role of TNF- $\alpha$ in colon cancer invasion and metastasis.
TROP-2 is a transmembrane glycoprotein expressed at high levels in a variety of human epithelial tumors. TROP-2 is strongly associated with tumor invasion and metastasis, and high levels of TROP-2 are associated with a poor prognosis in gastric carcinoma (8). However, the mechanism underlying TROP-2 overexpression in tumors remains unclear. 
The mechanism by which TROP-2 is upregulated in tumors may provide insights that could facilitate the development of approaches for early diagnosis and treatment.

In previous studies, both TROP- 2 and TNF- $\alpha$ were markedly expressed at the protein level in a large number of colon cancer tissue samples (12). Therefore, it was speculated that TNF- $\alpha$ may upregulate TROP-2 protein levels in colon cancer cells, thereby promoting tumor cell migration and invasion. The findings of the present study validate this hypothesis.

In the present study, the effect of various concentrations of TNF- $\alpha$ on TROP- 2 protein levels was examined in colon cancer cells. TROP-2 protein levels increased in cells incubated with low concentrations of TNF- $\alpha$ and decreased in cells incubated with higher concentrations. Maximum TROP-2 levels were observed in cells treated with $20 \mu \mathrm{g} / 1 \mathrm{TNF}-\alpha$. It is hypothesized that TROP-2 levels are decreased in cells treated with high concentrations of TNF- $\alpha$ potentially due to increased cytotoxicity. Wound healing and cell invasion were enhanced in cells treated with $20 \mu \mathrm{g} / 1 \mathrm{TNF}-\alpha$ compared with control untreated cells. Thus, the present data demonstrated that low concentrations of TNF- $\alpha$ upregulated TROP- 2 protein expression and promoted colon cancer cell migration and invasion.

To further confirm the hypothesis that low concentrations of TNF- $\alpha$ promote invasion in colon cancer cells by upregulating TROP-2, expression of TROP-2 was silenced using siRNA technology. Cell migration and invasion were significantly inhibited in TROP-2 siRNA-transfected HCT-116 cells treated with TNF- $\alpha$, compared with control siRNA-transfected cells. These data demonstrate that the inflammatory cytokine TNF- $\alpha$ promotes migration and invasion in colon cancer cells by upregulating TROP-2.

To date, there have been no reports describing the mechanism by which inflammatory cytokines, such as TNF- $\alpha$, upregulate TROP-2. Choo et al (20) demonstrated that TNF- $\alpha$ may induce colon cancer cells to metastasize to the lungs by activating the ERK signaling pathway. Hagemann et al (21) reported that TNF- $\alpha$ secretion by tumor-associated macrophages promotes the invasion and metastasis of breast cancer cells by activating the JNK pathway and upregulating MMPs and VEGF. Muthukumaran et al reported that TNF- $\alpha$ enhances the metastatic potential of SKA and SKOV-3 ovarian cancer cells by activating the JNK signaling pathway and modulating CD44 levels (22). Therefore, it was hypothesized in the present study that TNF- $\alpha$ may upregulate TROP-2 in HCT-116 cells by activating the MAPK pathway. The results demonstrated that p-ERK $1 / 2$ levels significantly increased in cells treated with TNF- $\alpha$ and this effect was significantly inhibited in cells pretreated with PD98059, a specific ERK1/2 inhibitor. The effect of PD98059 on wound healing and invasion assays suggested that the TNF- $\alpha$-induced tumor migration and invasion may be mediated by ERK1/2. By contrast, the phosphorylation levels of the MAPK proteins p38 and JNK did not significantly change in cells treated with TNF- $\alpha$, suggesting that these proteins do not serve a role in the TNF- $\alpha$-induced upregulation of TROP-2.

In conclusion, TNF- $\alpha$ is a key inflammatory cytokine in the tumor microenvironment, and the present results suggest that it may promote colon cancer invasion by upregulating TROP-2 expression via the ERK1/2 signaling pathway. Therefore, the
ERK1/2 pathway may represent a potential therapeutic target for the treatment of colon cancer.

\section{Acknowledgements}

The present study was partly supported by the National Natural Science Foundation of China (grant nos. 81-172317, 30972887, and 81572856) and Beijing Municipal Administration of Hospitals Clinical Medicine Development of Special Funding Support (grant no. ZYLX201504). The authors would like to thank the members of the Beijing Friendship Hospital laboratory for providing technical assistance and our colleagues for help during the course of this study.

\section{References}

1. Eiró $\mathrm{N}$ and Vizoso FJ: Inflammation and cancer. World $\mathrm{J}$ Gastrointest Surg 27: 62-72, 2012.

2. Calcinotto A, Grioni M, Jachetti E, Curnis F, Mondino A Parmiani G, Corti A and Bellone M: Targeting TNF- $\alpha$ to neoangiogenic vessels enhances lymphocyte infiltration in tumors and increases the therapeutic potential of immunotherapy. J Immunol 188: 2687-2694, 2012.

3. Ikemoto S, Sugimura K, Yoshida N, Wada S, Yamamoto K and Kishimoto T: TNF alpha, IL-1 beta and IL- 6 production by peripheral blood monocytes in patients with renal cell carcinoma. Anticancer Res 20: 317-321, 2000.

4. Wu Y, Deng J, Rychahou PQ, Qiu S, Evers BM and Zhou BP: Stabilization of snail by NF-kappaB is required for inflammation-induced cell migration and invasion. Cancer Cell 15: 416-428, 2009.

5. Matsushita S, Nitanda T, Furukawa T, Sumizawa T, Tani A, Nishimoto K, Akiba S, Miyadera K, Fukushima M, Yamada Y, et al: The effect of a thymidine phosphorylase inhibitor on angiogenesis and apoptosis in tumors. Cancer Res 59: 1911-1916, 1999.

6. Fong D, Spizzo G, Gostner JM, Gastl G, Moser P, Krammel C, Gerhard S, Rasse M and Laimer K: TROP2: A novel prognostic marker in squamous cell carcinoma of the oral cavity. Mod Pathol 21: 186-191, 2008.

7. Fong D, Moser P, Krammel C, Gostner JM, Margreiter R, Mitterer M, Gastl G and Spizzo G: High expression of TROP2 correlates with poor prognosis in pancreatic cancer. Br J Cancer 99: 1290-1295, 2008.

8. Mühlmann G, Spizzo G, Gostner J, Zitt M, Maier H, Moser P, Gastl G, Zitt M, Müller HM, Margreiter R, et al: TROP2 expression as prognostic marker for gastric carcinoma. J Clin Pathol 62: 152-158, 2009.

9. Bignotti E, Todeschini P, Calza S, Falchetti M, Ravanini M, Tassi RA, Ravaggi A, Bandiera E, Romani C, Zanotti L, et al: Trop-2 overexpression as an independent marker for poor overall survival in ovarian carcinoma patients. Eur J Cancer 46: 944-953, 2010.

10. Pak MG, Shin DH, Lee $\mathrm{CH}$ and Lee MK: Significance of EpCAM and TROP2 expression in non-small cell lung cancer. World J Surg Oncol 10: 53, 2012.

11. Trerotola M, Rathore S, Goel HL, Li J, Alberti S, Piantelli M, Adams D, Jiang Z and Languino LR: Trop-2 and alpha-2beta1 integrin surface receptors as markers of putative human prostate cancer stem cells. Am J Transl Res 2: 135-144, 2010.

12. Zhao P, Yu HZ and Cai JH: Clinical investigation of TROP-2 as an independent biomarker and potential therapeutic target in colon cancer. Mol Med Rep 12: 4364-4369, 2015.

13. Stepan LP, Trueblood ES, Hale K, Babcook J, Borges L and Sutherland CL: Expression of Trop2 cell surface glycoprotein in normal and tumor tissues: Potential implications as a cancer therapeutic target. J Histochem Cytochem 59: 701-710, 2011.

14. Schnider CA, Rasband WS and Eliceiri KW: NIH Image to ImageJ: 25 years of image analysis. Nat Methods 9: 671-675, 2012 .

15. Wang Y, Guo Q, Zhao Y, Chen J, Wang S, Hu J and Sun Y: BRAF-activated long non-coding RNA contributes to cell proliferation and activates autophagy in papillary thyroid carcinoma. Oncol Lett 8: 1947-1952, 2014. 
16. Colotta F, Allavena P, Sica A, Garlanda C and Mantovani A Cancer related inflammation, the seventh hallmark of cancer: Links to genetic instability. Carcinogenesis 30: 1073-1081, 2009.

17. Wolczyk D, Zaremba-Czogalla M, Hryniewicz-Jankowska A, Tabola R, Grabowski K, Sikorski AF and Augoff K: TNF- $\alpha$ promotes breast cancer cell migration and enhances the concentration of membrane-associated proteases in lipid rafts. Cell Oncol (Dordr) 39: 353-363, 2016.

18. Gao ZL, Yang CC, Xu XH, et al: Experimental study on TNF- $\alpha$ promoting invasion and metastasis of oral cancer cells by regulating MMPs. Stomatology 34: 9-12, 2014.

19. Hong H, Jiang L, Lin Y, He C, Zhu G, Du Q, Wang X, She F and Chen Y: TNF-alpha promotes lymphangiogenesis and lymphatic metastasis of gallbladder cancer through the ERK1/2/AP-1/VEGF-D pathway. BMC Cancer 16: 240, 2016.
20. Choo MK, Sakurai H, Koizumi K and Saiki I: Stimulation of cultured colon 26 cells with TNF-alpha promotes lung metastasis through the extracellular signal-regulated kinase pathway. Cancer Lett 230: 47-56, 2005

21. Hagemann T, Wilson J, Kulbe H, Li NF, Leinster DA, Charles K, Klemm F, Pukrop T, Binder C and Balkwill FR: Macrophages induce invasiveness of epithelial cancer cells via NF-kappaB and JNK. J Immunol 175: 1197-1205, 2005.

22. Muthukumaran N, Miletti-González KE, Ravindranath AK and Rodríguez-Rodríguez L: Tumor necrosis factor-alpha differentially modulates CD44 expression in ovarian cancer cells. Mol Cancer Res 4: 511-520, 2006. 